\title{
Relationship between the Effect of Inclusions on the Endurance Limits and the Work Hardening Behaviours of Carbon Steels*
}

\author{
By Masae SUMITA,*** Iku UCHIYAMA, ** and Toru ARAKI***
}

\section{Synopsis}

The effect of inclusions on fatigue properties of steel was examined and discussed. Materials containing $\mathrm{FeO}$ type inclusions, those containing $\mathrm{Mn}$-silicate inclusions, and those containing very few inclusions were used. Some of them were carburized and subsequently heat-treated to change the strength level of the matrix. The results obtained were mainly as follows.

(1) Although the effect of inclusions in the low carbon materials and in the as-carburized materials on the endurance limits was small, the endurance limit of the high-strengthened materials was noticeably decreased by inclusions. The trend was outstanding when the inclusions acted largely as the stress raisers.

(2) The effect of inclusions on the endurance limit was correlated to the work hardening coefficient, $n$, defined by $\sigma=c \varepsilon^{n}$, in terms of rate of the decrease of the endurance limits due to inclusions, $W$, as follows:

$$
W=i(A-n)
$$

where $i$ is the variable depending on the state (size, shape, amount, etc.) of inclusions and $A$ is a constant.

(3) The effect of inclusions on the endurance limit was explained from a phenomenological viewpoint by a model based on the work hardening.

\section{Introduction}

The effects of inclusions on the fatigue properties of the steels have been considered from a dynamical viewpoint to depend on the property of the matrix, of the inclusions themselves, and of the boundary between the matrix and inclusions. ${ }^{1,2}$ However, as no adequate way to examine the adherence between the matrix and inclusions has been established, the effect of inclusions can only be considered from the former two.

On the other hand, it is quite probable that voids are always present or make ready appearance in a fatigue specimen because of the following reasons: between inclusions and matrix, 1) during rolling the deformability is different, 2) during cooling the thermal expansion coefficient is different, and 3) under alternating stress, the adherence is weakened by the tensile stress given rise to in the inclusions. This can be a reasonable substitute for the third of these three factors mentioned above.

The stress concentration around an inclusion has been calculated from the viewpoint of elasticity by Edwards $^{1)}$ and others. ${ }^{2,3)}$ Atkinson $^{4)}$ defined elastically the inclusion index by regarding inclusions as voids. These ideas, however, can only be effective when the material is an ideal elastic body. Therefore, the inclusion index is not appropriate for application to practical materials, where the plastic deformation is considered to precede and control the initiation of microcracks. ${ }^{5-9)}$

The purpose of the present research was to investi- gate systematically the effects of inclusions on fatigue properties with respect to the properties of matrices. The former was examined by varying the state of existence of inclusions, i.e., the kind, size, shape, and amount in low carbon steels; steels that contain FeO type inclusions, those containing Mn-silicate type inclusions, and those containing very few inclusions were prepared. While the latter was done by preparing some of the specimens to various strength levels through carburization and heat treatments without changing the state of existence of inclusions.

In alternating fatigue test, the relationships between the initiation and propagation of cracks and the endurance limit and those between features of matrix and fatigue properties were examined, and the effects of inclusions on the endurance limits were analysed on the basis of the work hardening.

\section{Experimental Procedures}

1. Materials

1. Melting

Four kinds of steels were prepared.

(1) The steels containing FeO type inclusions (Mark: A81) were made by open-melting $6 \mathrm{~kg}$ of electrolytic iron in a high frequency electric furnace.

(2) The steels having very few inclusions (Mark: V81) were made by vacuum-melting and deoxidizing with $0.05 \%$ C. Chemical composition of the material was almost the same as that of A81.

(3) The steels containing Mn-silicate type inclusions (Mark: A73) were made by open-melting $50 \mathrm{~kg}$ of electrolytic iron and by deoxidizing with $\mathrm{Si}-\mathrm{Mn}$ alloy.

(4) The steels having very few inclusions and the same chemical compositions as those of A73 (Mark: V73) were made by vacuum-melting $6 \mathrm{~kg}$ of electrolytic iron.

The ingots, each weighing $c a .5 \mathrm{~kg}$, were hot-rolled $\left(1200^{\circ}\right.$ to $1000^{\circ} \mathrm{C}$ ) down to about $3.0 \mathrm{~mm}$ thick sheets, machined to test pieces shown in Fig. 1, and electrolytically polished in Morris's electrolyte. Some of the sheets were machined so that the rolling direction would be perpendicular to the long axis of the fatigue specimens. $\mathrm{V}$-notched $(0.3 \mathrm{~mm}$ deep and $30^{\circ}$ notch angle) specimens were prepared for $\mathrm{C} 400$ V73 and V73 steels. The chemical compositions of the steels are shown in Table 1.

The optical micrographs of typical inclusions in steels A81 and A73 and the electron micrographs of

* Partially published in Tetsu-to-Hagané, 57 (1971), 298, in Japanese. English version received November 28, 1973.

** Iron and Steel Division, National Research Institute for Metals, Nakameguro, Meguro-ku, Tokyo 153.

*** Department of Metallurgy, Faculty of Engineering, The University of Tokyo, Hongo, Bunkyo-ku, Tokyo 113. 
Table 1. Chemical compositions of steels

\begin{tabular}{|c|c|c|c|c|c|c|c|c|}
\hline & C & $\mathrm{Si}$ & Mn & $\mathrm{Al}$ & $\mathrm{P}$ & $\mathrm{S}$ & $\mathrm{O}$ & $\mathrm{N}$ \\
\hline A81 & 0.005 & 0.002 & 0.003 & 0.007 & 0.001 & 0.002 & 0.127 & 0.0041 \\
\hline V81 & 0.007 & 0.003 & $<0.001$ & 0.002 & N. D. & 0.005 & 0.019 & 0.0010 \\
\hline A73 & 0.017 & 0.19 & 0.59 & 0.002 & 0.004 & 0.006 & 0.042 & 0.0030 \\
\hline V73 & 0.010 & 0.25 & 0.45 & 0.003 & N. D. & 0.004 & 0.020 & 0.0018 \\
\hline
\end{tabular}

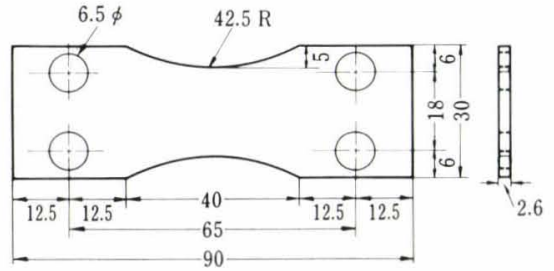

(a) For fatigue test

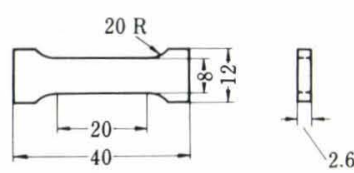

(b) For tension test

Fig. 1. Dimensions of test pieces $(\mathrm{mm})$

various specimens, all as etched with 3\% nital, are shown in Photos. 1 and 2. The inclusions in A81 are mainly $\mathrm{FeO}$, which remained almost undeformed by hot-rolling as shown in Photo. 1 (a). The inclusions in A73 are Mn-silicate; they were deformed to types A, B, or C, as defined by the JIS. G0555, by rolling. 2. Carburizing and Heat Treatment

Some of the specimens were gas-carburized at $910^{\circ} \mathrm{C}$ for $8 \mathrm{hr}$ to be $0.25 \% \mathrm{C}$, and then heat-treated to various strength levels and in various microstructures. These specimens were machined down to $2.6 \mathrm{~mm}$ thick specimens. The details of the specimens used are shown in Table 2 .

\section{Fatigue Test and Tensile Test}

A small alternating bending fatigue testing machine of the Schenck type was used with a loading frequency of 3000 cycles/min. The bending stress for each specimen was estimated using the following equation:

$$
\sigma=r \cdot T \cdot E / 2 L
$$

where $r$ is the bending radius ( $\mathrm{rad}), \mathcal{T}$, the thickness of specimen (mm), $E$, the Young's Modulus $\left(\mathrm{kg} / \mathrm{mm}^{2}\right)$, and $L$, the length of specimen ( $\mathrm{mm})$.

The tensile properties were determined in an Instron type machine at a crosshead speed of $0.2 \mathrm{~cm} /$ $\min$.

\section{Results}

\section{1. $S-\mathcal{N}$ Curves}

Typical S-N curves for specimens are shown in Fig. 2. The endurance limits for all specimens are shown in Table 3 with other mechanical properties. The following observations were obtained.

(1) The endurance limits of the steels A81, V81, A73, and V73 are nearly the same regardless the

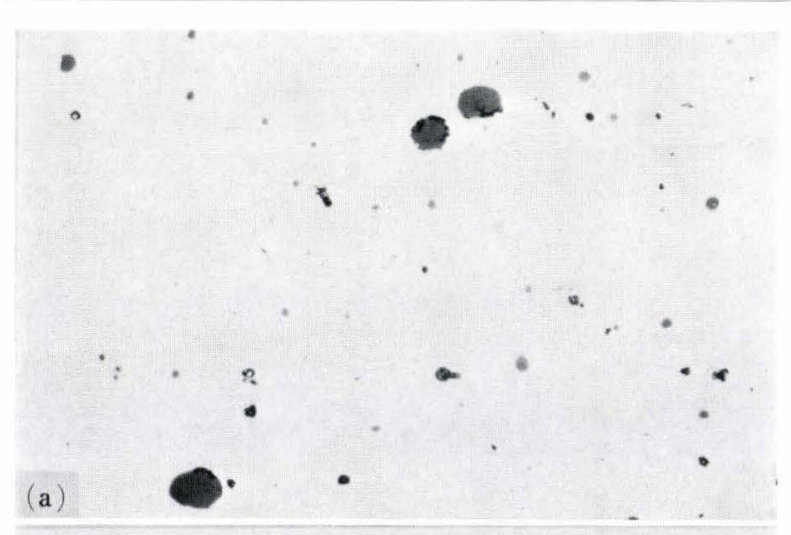

(a)

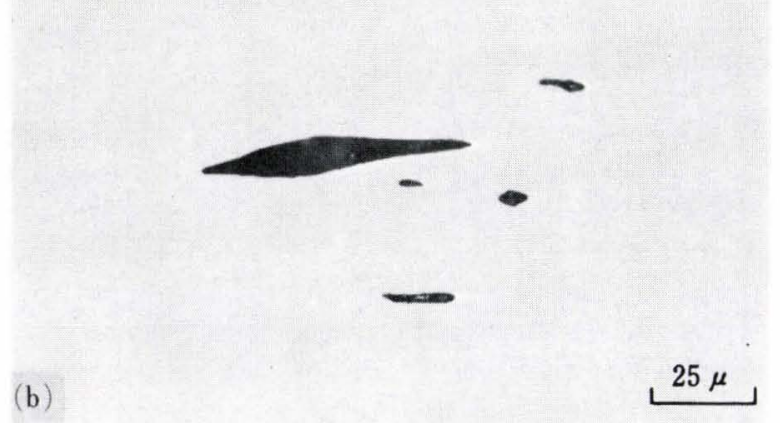

Photo. 1. Optical micrographs of (a) FeO type inclusions in an A81L specimen, and (b) Mn-silicate type inclusions in an $\mathrm{A} 73 \mathrm{~L}$ specimen

state of existence, i.e., the shape, kind, or amount, of inclusions.

(2) The endurance limits of the as-carburized steels (AC's in Table 2) with pearlite are $20 \%$ higher than those of the non-carburized ones, though no effect of the inclusions on the endurance limits is found (Table 3). This fact will be discussed later by considering the micro-work-hardenability around the inclusions.

(3) For the carburized and heat-treated steels, when the long axis of the specimens is parallel to the rolling direction (identified by the postscript L), the endurance limit is generally higher for vacuum-melted steels than for the open-melted steels, the trend becoming more marked with decrease of the tempering temperature.

(4) When the long axis of specimen is perpendicular to the rolling direction (identified by the postscript $T$ ), the rate of the decrease in the endurance limits of A73T steels becomes the greater, the lower the tempering temperature, being as much as $45 \%$ of the original for $400^{\circ} \mathrm{C}$ tempering. On the other hand, no effect of the rolling direction is found for V73T steels that contain very few inclusions. This is evidently due to that the inclusions are of types $\mathrm{A}$ and B. 
(5) The endurance limits of the $\mathrm{V}$-notched specimens of steels C400-V73 and V73 were lowered by about $80 \%$ and $33 \%$ respectively compared with those of the no-notched counterparts. The fact that the endurance limit was lowered by $33 \%$ in V73, which was considered not to be influenced by inclusions before, implies that even in such a steel the inclusions can influence the endurance limit acting as macro-notches if the state of existence of inclusions is favourable for such effect.

\section{Initiation of Microcracks from Inclusions and their Pro- pagation}

For certain ones of the A73T and C500-A73T, the machine was stopped several times during the fatigue tests, and the numbers and the mean lengths of microcracks, either associated with inclusions ( $i$ and $l_{i}$ ) or not associated $\left(l_{n}\right)$, were determined in an optical microscope by directly counting and measuring in 100 fields of observation selected at random at the magnification of 400 . By the quantities $R_{i}$, and $R_{p}$ defined by

$$
\begin{aligned}
& R_{i}=i / t \\
& R_{p}=l_{i} / l_{n}
\end{aligned}
$$

where $t$ is the total number of the microcracks, the effect of inclusions on fatigue can be evaluated. The relationships between the cycles and $R_{i}$ or $R_{p}$ are shown in Fig. 3. It will be observed:

(1) In the steel C500-A73T, the microcracks are initiated from inclusions within $10 \%$ of the fatigue life.

(2) The $R_{i}$ and $R_{p}$ of the steel C500-A73T, which is considerably sensitive to inclusions under alternating stress, are large at the earlier stage of the fatigue, but decrease rapidly to approach those at the time of failure. However, the trend is unclear in the insensitive steel A73T. Therefore, it may be concluded that, when the inclusions have adverse influences on fatigue properties, the microcracks are apt to be initiated preferentially at inclusions in the earlier stage of fatigue life.

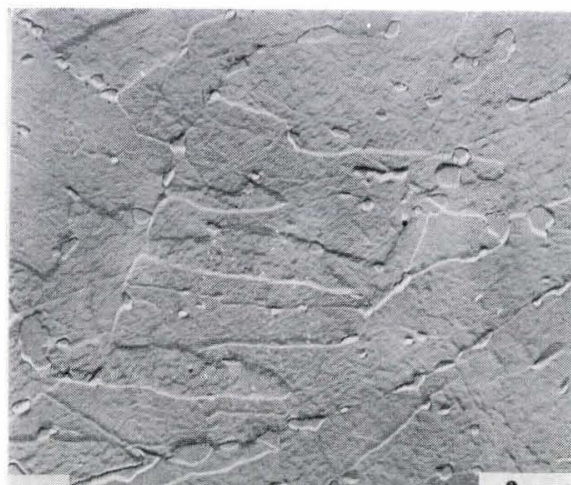

(a)
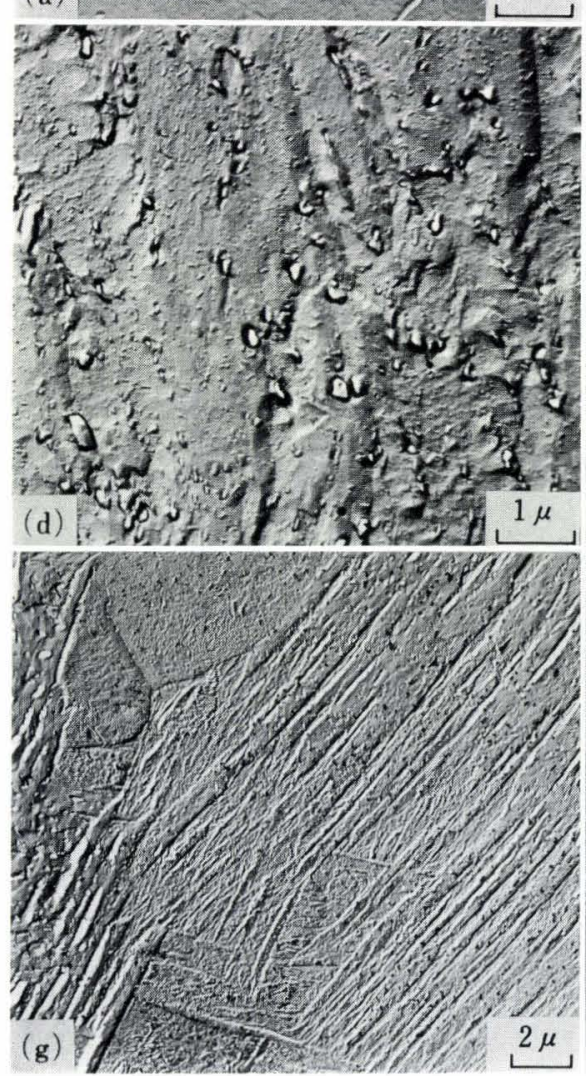
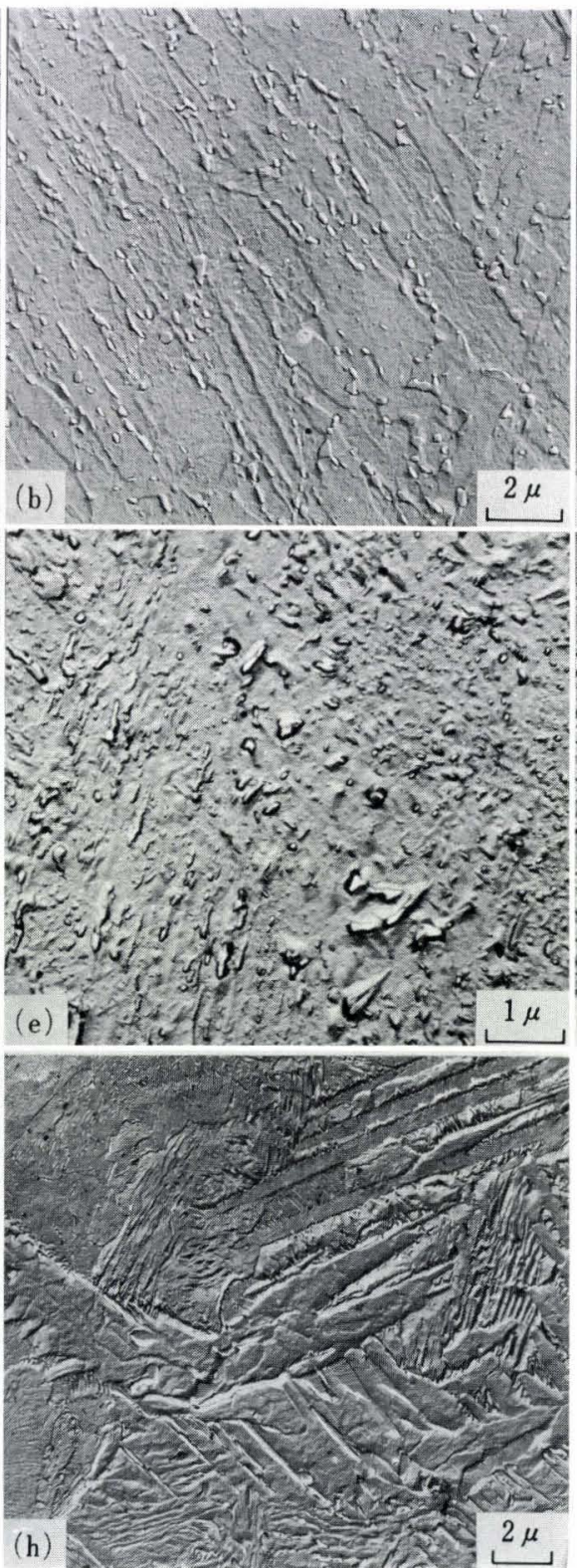
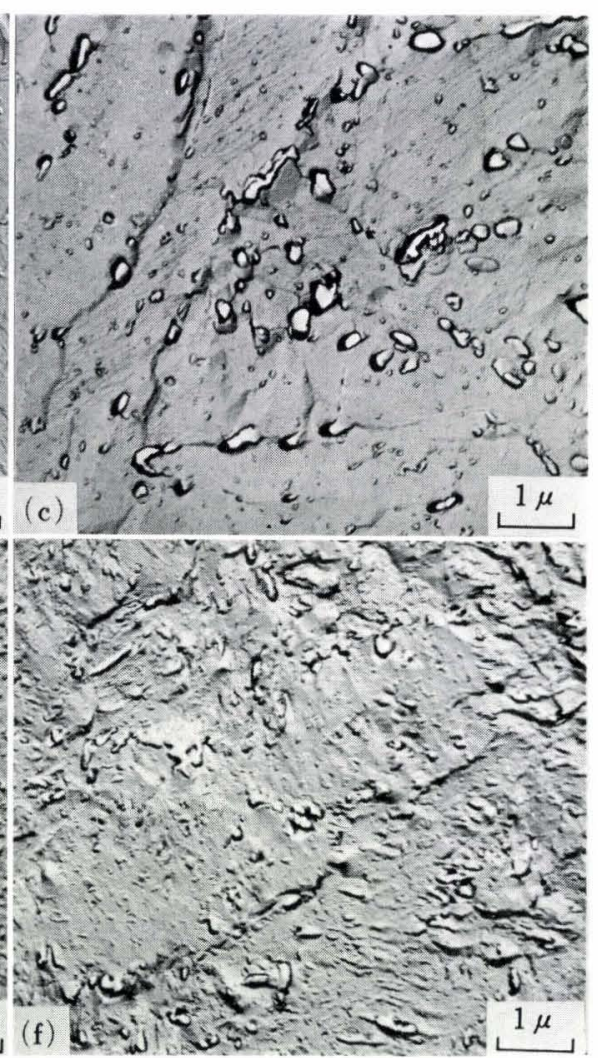

Photo. 2. Electron micrographs of various specimens. Etched by $3 \%$ nital

(a) C620-V81 specimen

(b) C620-A73 specimen

(c) C500-A81 specimen

(d) C500-A73 specimen

(e) C400-A81 specimen

(f) C400-A73 specimen

(g) C-OIL-A81 specimen

(h) C-OIL-A73 specimen 
(3) The values of $R_{i}$ and $R_{p}$ for the main part of fatigue life are as follows: $R_{i}(\mathrm{~A} 73 \mathrm{~T})=0.46, R_{p}(\mathrm{~A} 73 \mathrm{~T})$ $=1.1, R_{i}(\mathrm{C} 500-\mathrm{A} 73 \mathrm{~T})=0.84$, and $R_{p}(\mathrm{C} 500-\mathrm{A} 73 \mathrm{~T})=$ 2.8 .

The shape of the inclusions in the steel A81 is mainly spheroidal, but that in A73T is various; namely type
A, Type B, or type C. Therefore, it is submitted that the fatigue process of the steel A73T, with the long axis of specimen perpendicular to the rolling direction, is to be ruled by the inclusions of type A or type $\mathrm{B}$, whereas that of the steel $\mathrm{A} 73 \mathrm{~L}$, with the long axis of specimen is parallel to the rolling direction, is to

Table 2. Details of specimens tested*

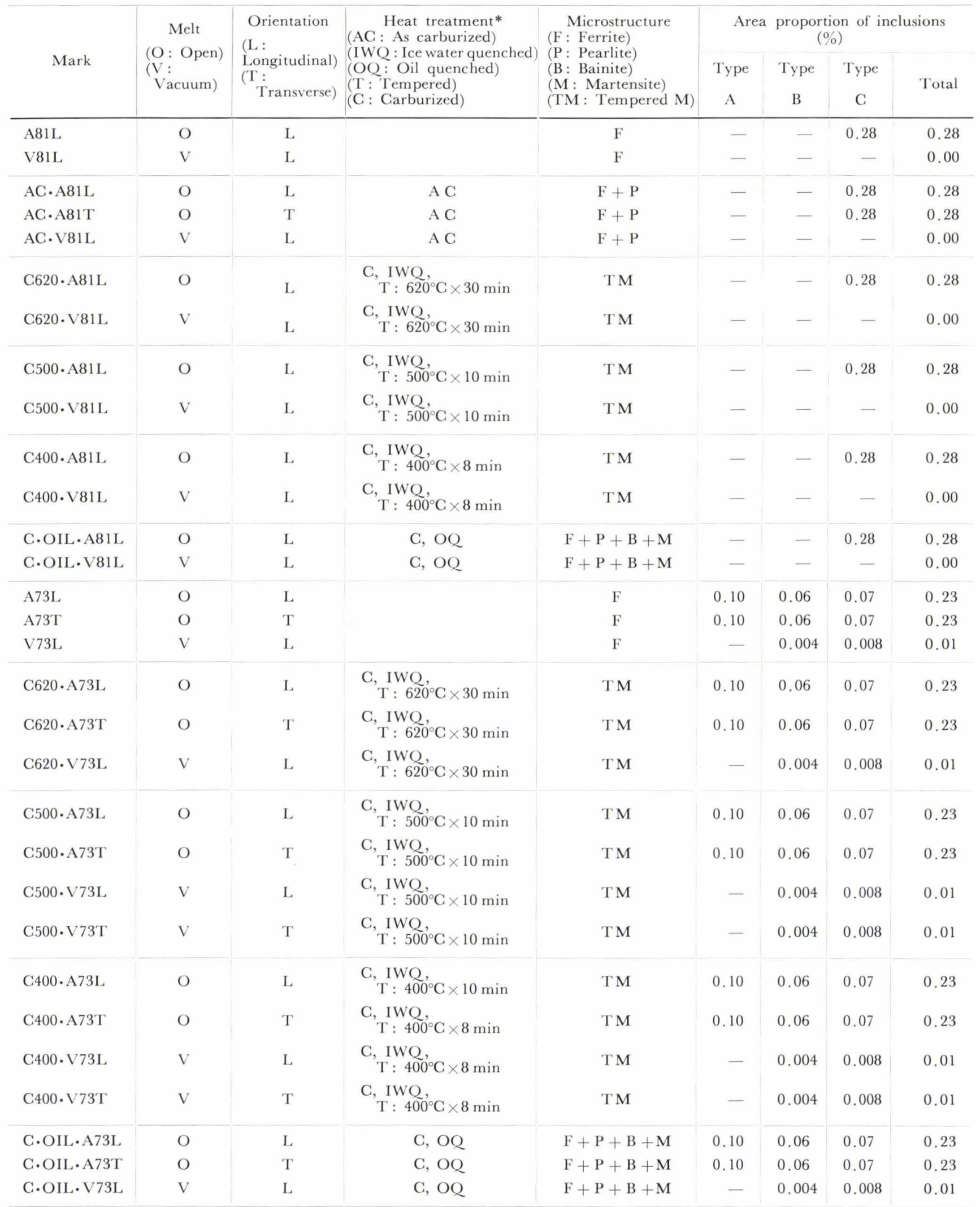

* Carburizing temperature: $910^{\circ} \mathrm{C} \times 8 \mathrm{hr}$, Quenching temperature: $850^{\circ} \mathrm{C} \times 10 \mathrm{~min}$ 
be ruled by the inclusions of type $\mathrm{C}$.

Figure 4 shows the relationship between the ratio of microcracks associated with inclusions of types $\mathrm{A}$ and $\mathrm{B}\left(\mathcal{N}_{m(A, B)}\right)$ to those associated with inclusions of types $\mathrm{A}, \mathrm{B}$, and $\mathrm{C}\left(\mathcal{N}_{m(A, B, C)}\right)$ on the ordinate and the ratio of area fraction of inclusions of types $\mathrm{A}$ and $\mathrm{B}$

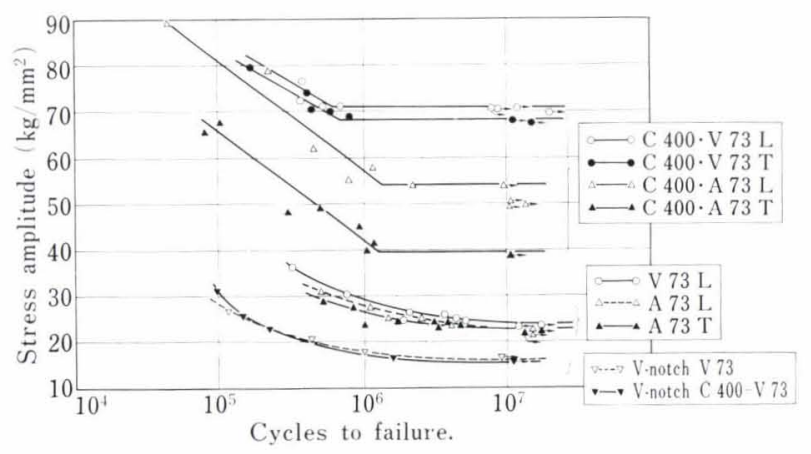

Fig. 2. Example of S-N curves
$\left(A \cdot F_{(A, B)}\right)$ to that of inclusions of types $\mathrm{A}, \mathrm{B}$ and $\mathrm{C}$ $\left(A . F_{\left.{ }_{(A, B, C)}\right)}\right.$ on the abscissa. When the measured value happens to fall in the upper side of the line $y=x$, the effect of inclusions of types $\mathrm{A}$ and $\mathrm{B}$ on crack initiation is larger than that of type $\mathrm{C}$ inclusions. On the other hand, when the measured value is located in the lower side of the line $y=x$, the effect of type $\mathrm{C}$ inclusions on crack initiation is larger than that of types B and C. Therefore, Fig. 4 supports the above conclusions. Photograph 3 is an example of crack initiated from type $\mathrm{C}$ inclusions.

\section{Relationship between Microstructure and Effect of In- clusions on Fatigue}

As shown in Table 3, ultimate tensile strengths of the C500 series steels and the C-OIL series steels were nearly the same. However, the microstructures were different as shown in Photos. 2 and 4. Namely, the microstructure of the former consists of the tempered

Table 3. Mechanical properties

\begin{tabular}{|c|c|c|c|c|c|}
\hline Mark & $\begin{array}{l}\text { Hardness } \\
(\mathrm{Hv})\end{array}$ & $\begin{array}{l}\operatorname{UTS}\left(\sigma_{\mathrm{B}}\right) \\
\left(\mathrm{kg} / \mathrm{mm}^{2}\right)\end{array}$ & $\begin{array}{c}\text { Elongation }(\delta) \\
(\%)\end{array}$ & $\begin{array}{l}\text { Reduction of area } \\
(\phi)(\%)\end{array}$ & $\begin{array}{l}\text { Endurance limit } \\
\left(\sigma_{\omega}\right) \quad\left(\mathrm{kg} / \mathrm{mm}^{2}\right)\end{array}$ \\
\hline $\mathrm{A} 81 \mathrm{~L}$ & 120 & 29.0 & 45 & 65 & 22.0 \\
\hline V81L & 130 & 29.0 & 41 & 81 & 22.5 \\
\hline $\mathrm{AC} \cdot \mathrm{A} 81 \mathrm{~L}$ & 123 & 36.5 & 40 & 45 & 26.0 \\
\hline $\mathrm{AC} \cdot \mathrm{A} 81 \mathrm{~T}$ & 127 & 36.0 & 39 & 48 & 25.5 \\
\hline AC.V81L & 127 & 35.0 & 45 & 56 & 25.0 \\
\hline $\mathrm{C} 620 \cdot \mathrm{A} 81 \mathrm{~L}$ & 145 & 41.0 & 36 & 53 & 34.0 \\
\hline C620.V81L & 152 & 42.5 & 38 & 55 & 36.0 \\
\hline $\mathrm{C} 500 \cdot \mathrm{A} 81 \mathrm{~L}$ & 280 & 53.0 & 25 & 42 & 41.0 \\
\hline $\mathrm{C} 500 \cdot \mathrm{V} 81 \mathrm{~L}$ & 295 & 52.5 & 27 & 50 & 47.5 \\
\hline $\mathrm{C} 400 \cdot \mathrm{A} 81 \mathrm{~L}$ & 380 & 66.5 & 16 & 28 & 52.5 \\
\hline $\mathrm{C} 400 \cdot \mathrm{V} 81 \mathrm{~L}$ & 390 & 65.0 & 20 & 41 & 59.0 \\
\hline $\mathrm{C} \cdot \mathrm{OIL} \cdot \mathrm{A} 81 \mathrm{~L}$ & 290 & 55.0 & 10 & 17 & 40.5 \\
\hline $\mathrm{C} \cdot \mathrm{OIL} \cdot \mathrm{V} 81 \mathrm{~L}$ & 290 & 56.0 & 16 & 32 & 45.5 \\
\hline A73L & 120 & 29.0 & 49 & 71 & 23.0 \\
\hline A73T & 120 & 28.0 & 49 & 62 & 22.5 \\
\hline V73L & 120 & 31.5 & 51 & 79 & 23.5 \\
\hline $\mathrm{C} 620 \cdot \mathrm{A} 73 \mathrm{~L}$ & 195 & 52.0 & 31 & 54 & 32.5 \\
\hline $\mathrm{C} 620 \cdot \mathrm{A} 73 \mathrm{~T}$ & 205 & 50.5 & 27 & 52 & 30.0 \\
\hline $\mathrm{C} 620 \cdot \mathrm{V} 73 \mathrm{~L}$ & 190 & 54.5 & 33 & 62 & 40.0 \\
\hline $\mathrm{C} 500 \cdot \mathrm{A} 73 \mathrm{~L}$ & 290 & 70.5 & 21 & 40 & 43.0 \\
\hline $\mathrm{C} 500 \cdot \mathrm{A} 73 \mathrm{~T}$ & 290 & 68.0 & 16 & 38 & 33.0 \\
\hline C500.V73L & 305 & 73.5 & 21 & 53 & 50.5 \\
\hline $\mathrm{C} 500 \cdot \mathrm{V} 73 \mathrm{~T}$ & 300 & 68.0 & 22 & 53 & 49.5 \\
\hline $\mathrm{C} 400 \cdot \mathrm{A} 73 \mathrm{~L}$ & 410 & 83.5 & 13 & 32 & 53.5 \\
\hline $\mathrm{C} 400 \cdot \mathrm{A} 73 \mathrm{~T}$ & 410 & 80.0 & 8 & 17 & 38.5 \\
\hline C400.V73L & 420 & 88.0 & 15 & 48 & 70.5 \\
\hline $\mathrm{C} 400 \cdot \mathrm{V} 73 \mathrm{~T}$ & 420 & 83.0 & 16 & 48 & 68.0 \\
\hline C.OIL·A73L & 290 & 74.0 & 3 & 7 & 45.0 \\
\hline C.OIL.A73T & 290 & 70.0 & 2 & 5 & 34.0 \\
\hline C.OIL.V73L & 300 & 73.0 & 5 & 8 & 50.5 \\
\hline V-notch V73 & - & - & - & - & 18.0 \\
\hline V-notch C400-V73 & - & - & - & - & 17.5 \\
\hline
\end{tabular}



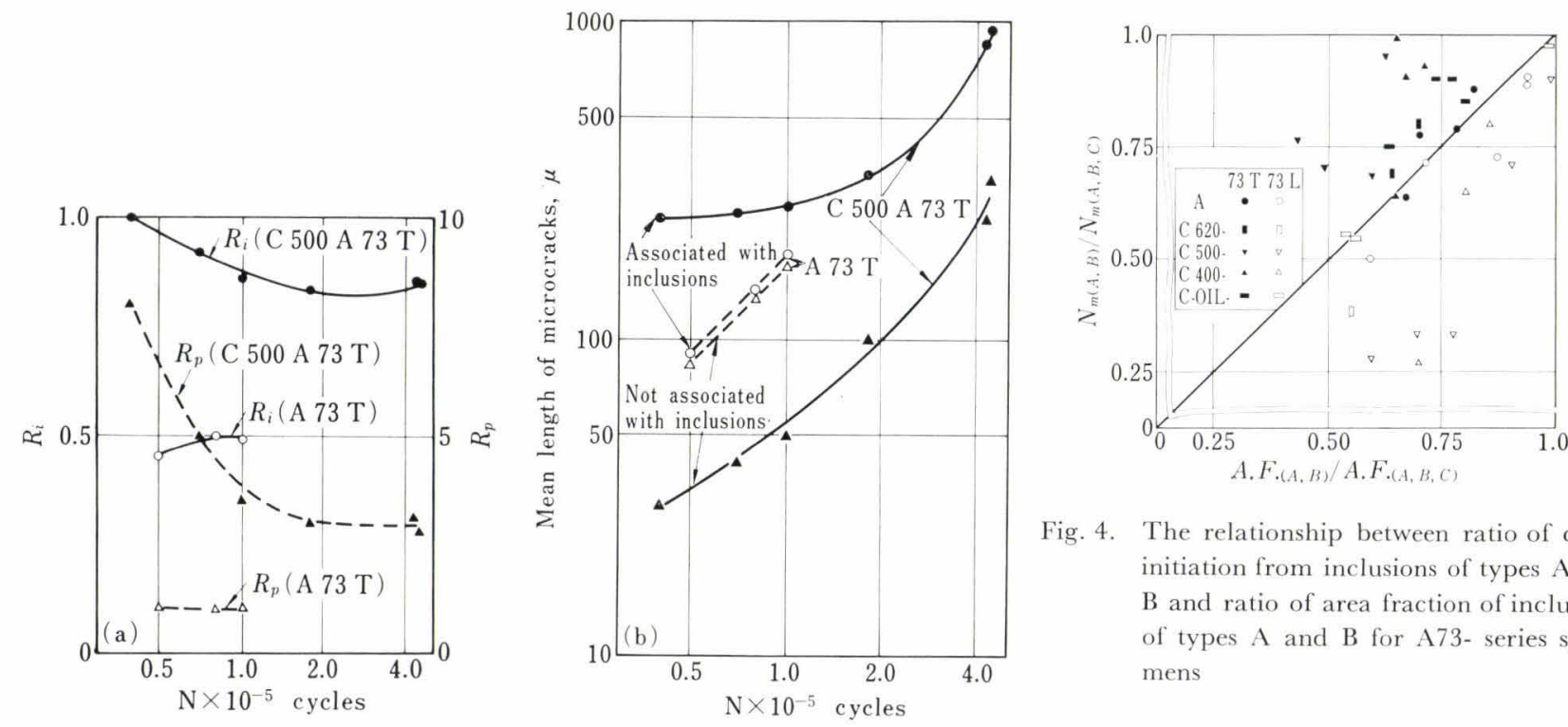

Fig. 4. The relationship between ratio of crack initiation from inclusions of types $\mathrm{A}$ and $\mathrm{B}$ and ratio of area fraction of inclusions of types $\mathrm{A}$ and $\mathrm{B}$ for A73- series specimens

Fig. 3. Initiation and propagation of cracks in A73T steels (a) changes in $R_{i}$ and $R_{p}$, and (b) changes in mean length of microcracks. Failure occurred at $1.01 \times$ $10^{5}$ cycles for $\mathrm{A} 73 \mathrm{~T}$, at $4.4 \times 10^{5}$ cycles for C500A73T.

$R_{i}$ : The ratio of the number of microcracks associated with inclusions to the total number of microcracks

$R_{p}$ : The ratio of the mean length of microcracks associated with inclusions to the mean length of microcracks not a ssociated with inclusions

martensite, whereas that of the latter is of the mixed structure; ferrite, bainite, martensite, and pearlite.

The ratios of the endurance limit, $\sigma_{\omega}$, to the tensile strength, $\sigma_{B}$ are shown in Fig. 5. As the $\sigma_{B}$ is proportional to the endurance limit in a wide strength level range, ${ }^{10}$ any effect of difference in $\sigma_{B}$ on the endurance limit can be thought as cancelled in comparing the ratios. It will be found in the figure that the ratios of the 81 -series steels are generally higher than those of the 73-series steels. The differences in $\sigma_{\omega} / \sigma_{B}$ between the vacuum-melted steels, V81's versus V73's are shown in Fig. 5 as $a_{1}$ in the case of homogeneous structures (tempered at $500^{\circ} \mathrm{C}$ ), and as $a_{2}$ in the case of oil-quenched-heterogeneous structures. The differences seem to have been caused by the differences in the chemical composition and microstructures because these steels both contain very few inclusions. That $a_{1}>a_{2}$ can be explained by the fact that the degree of the heterogeneity is greater in V81 owing to its lower hardenability.

The $b^{\prime} \mathrm{s}$ in Fig. 5, which are the differences of $\sigma_{\omega} / \sigma_{B}$ caused only by the difference in the homogeneity of the structures as shown in Photo. 4, represent the crosseffect of the microstructures in the effects of inclusions on endurance limits. Therefore, the decrease of the endurance limit in C-OIL-V81 should be larger than that in $\mathrm{C}-\mathrm{OIL}-\mathrm{V} 73$, as actually found to be $b_{1}>b_{3}$. It is not hard to understand that such a heterogeneous structure has an adverse influence on endurance limit, because it can contain many nuclei for crack initiation.

The $b_{5}$ for the A73T, in which the influence of in-

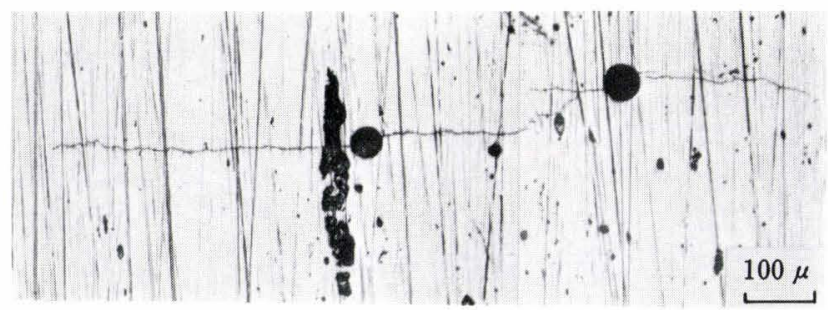

Photo. 3. Microcracks initiated from C type inclusions. C500A73L specimen. $9.0 \times 10^{4}$ cycles to failure

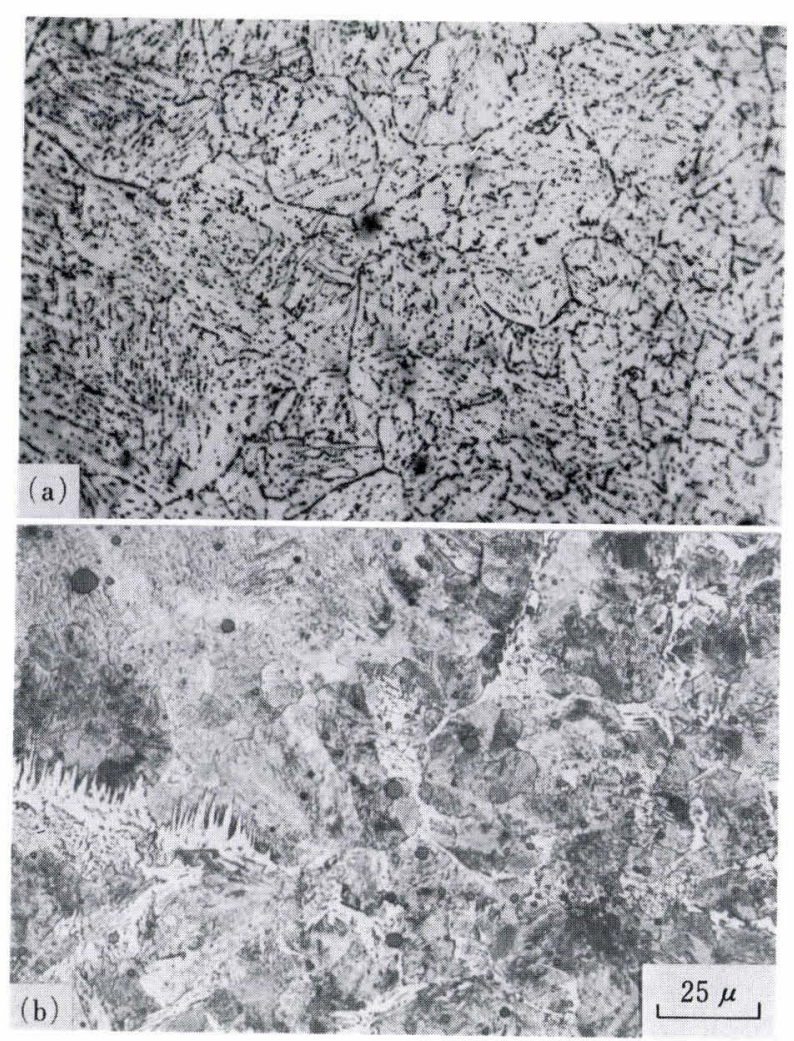

(a) C500-A81 specimen

(b) C-OIL-A81 specimen

Photo. 4. Microstructures of specimens

clusions for the endurance limit is the worst, is the smallest. This is due to that the effect of the microstructures has become cancelled by the increasing effect of the inclusions. 


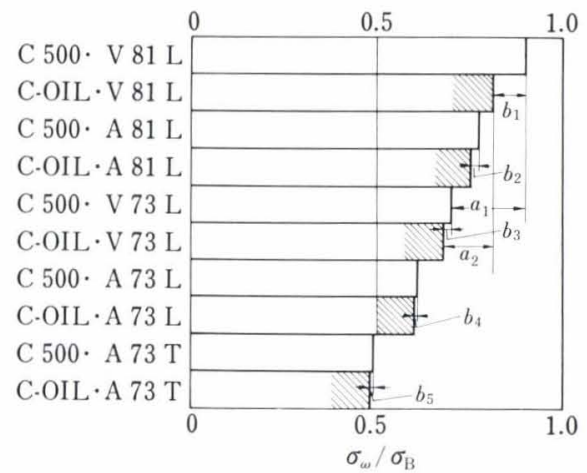

Fig. 5. The ratio of endurance limit $\left(\sigma_{\omega}\right)$ to tensile strength $\left(\sigma_{B}\right)$

$a$ : The difference of the ratio between V81-series specimens and V73-series specimens

$b$ : The difference of the ratio between C500-series specimens (homogeneous microstructure) and C. OIL-series specimens (heterogeneous microstructure)

\section{Discussion}

1. Relationship between Work Hardening and Initiation of Microcracks from Inclusions and their Propagation

The work hardening coefficient has been taken to represent the matrix in considering the relation between properties of steel matrix and fatigue properties in connection with inclusions by the following reasons.

In a specimen with a small plastic deformability, the amount of plastic deformation at the tip of a microcrack is small, because the difference of the tensile strength over the yield stress is small. In such a specimen, extremely speaking, the microcrack grows brittlely due to the elastic strain, though, in general, specimens fracture under alternating stress as a result of repetition of an elastic strain and a micro-plastic strain. On the other hand, in a specimen with a larger deformability, local yielding is initiated easily at the tip of micro-cracks, ${ }^{11)}$ and the stress concentration at the root of the crack will be relaxed and the propagation of the crack will be arrested. At the same time, however, the work hardening keeps progressing, and the crack starts to propagate when the amount of work hardening reaches a certain limit. Thus, it will be that the easiness of crack propagation depends on the deformability of matrix or the ratio of yield strength to tensile strength. Since the deformability is related to the work hardening, the condition for crack propagation may be evaluated quantitatively by the work hardening coefficient of matrix.

Here, the factor that controls the crack propagation should really be the easiness of the plastic deformation at the tip of the crack, that is, the micro-work hardenability.

As it is difficult to measure this quantity directly, however, it is assumed that the micro-work hardenability is the same as the macro-work hardenability. Since the size of the plastically deformed region at crack tips such as sub-grains has been found to increase with the rate of the crack propagation to correlate to the stress intensity factor, ${ }^{12}$ this assumption appears to be adequate.

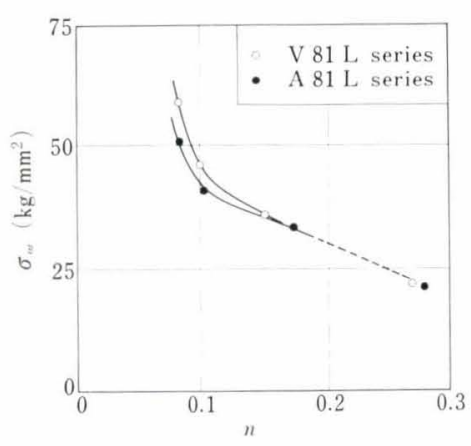

Fig. 6.

The relationship between endurance limit $\left(\sigma_{\omega}\right)$ and work-hardening coefficient (n) of 81 -series specimens

Further, dynamical stress-strain curve, i.e., that under alternating stress, is generally obtained from the hysteresis loop after the work hardening has been saturated.13,14) The saturation appears generally at a few percent of fatigue life, ${ }^{15)}$ within which time micro-cracks are also initiated from stress raisers such as inclusions. ${ }^{16,17)}$ Therefore, it is questionable whether the work hardening coefficient obtained from the dynamical stress-strain curve would apply to the process of the crack propagation.

Thus, the work hardening coefficient $n$ defined by $\sigma=c \varepsilon^{n}$ was used to represent the work hardenability of matrix. Although the behaviours of the work hardening under tensile stress and those under alternating stress are not necessarily the same, ${ }^{18)}$ it is possible to use $n$ for $n^{\prime}$, the work hardening coefficient under alternating stress, by assuming that the dynamical recovery due to the compression stress under alternating stress would be proportional to the hardening due to the tensile stress.

Inclusions are considered as the pre-exsisted crack because inclusions bad for fatigue are considered not to adhere to the matrix. The crack initiation from such inclusions, therefore, can be described using the relation between the crack propagation and the work hardenability of matrix, $n$.

The process of crack initiation and that of crack propagation have usually been discussed separately. However, this is inadequate for specimens containing many inclusions, because it is not one single crack that grows to fracture, but the main crack grows as it is joined by other cracks. Because of the stress concentration given rise to in the vicinity of the inclusions and at the tip of the crack, inclusions which are located in front of the main crack promote the crack propagation whether the crack had been initiated from the inclusions or not.

The relationships between $n$ and the endurance limit, $\sigma_{\omega}$, are shown in Figs. 6 and 7 . The $n$ was calculated by the method of least squares on the true stress-true strain curves. It will be seen that the difference in $\sigma_{\omega}$ between the vacuum-melted steels (V81's and V73's) and air-melted steels (A81's and A73's) decreases with the increase of $n$, becoming negligible at $n>0.16$. Since these differences represent the magnitude of the effect of inclusions on $\sigma_{\omega}$ as described before, the effect can be said to decrease with the increase of $n$. The difference in the shape of the curves between the 81 -series specimens and the 73-series specimens is probably a result of the difference in the 


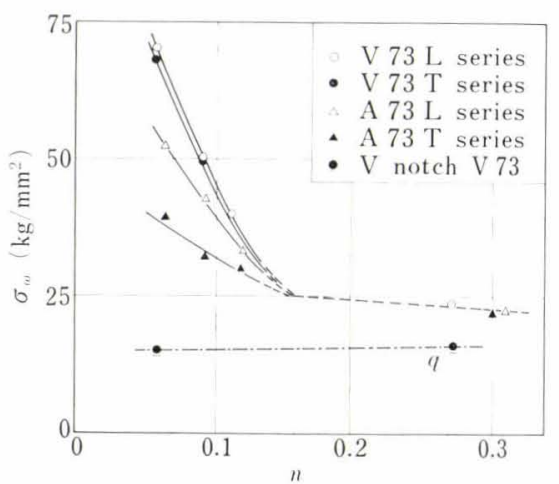

Fig. 7. The relationship between endurance limit $\left(\sigma_{\omega}\right)$ and work-hardening coefficient $(n)$ of 73 -series specimens

hardenability owing to manganese. The critical value of $n$, beyond which the inclusions scarcely influence the endurance limits, will undoubtedly change according to the structure of matrix and the state of existence of inclusions. It is predicted that with the increase of the effect of inclusions the relation between $\sigma_{\omega}$ and $n$ will approach the line $q$ for the $\mathrm{V}$-notched specimens.

Data of Figs. 6 and 7 are replotted in Fig. 8 to show the rates of reduction of the endurance limits due to inclusions, $W$, the percentage at a given $n$ of $\sigma_{\omega}$ of the steel containing inclusions to $\sigma_{\omega j}$ of the steel containing very few inclusions. It will be seen that $W^{\prime}$ s and $n$ are linearly related as follows:

$$
\begin{aligned}
& W_{81 L}=-168(0.155-n) \\
& W_{73 L}=-240(0.154-n) \\
& W_{73 T}=-410(0.163-n) .
\end{aligned}
$$

where, as may be seen in Figs. 6 and 7, Eq. (1) is valid for $0.16>n>0.08$, and Eqs. (2) and (3) for $0.16>n>0.06$.

Since the work hardening coefficient $n$ represents the properties of the matrix, the difference in the proportionality constants in those equations is due to the difference with respect to the inclusions. It is reasonable that the constant for the $73 \mathrm{~T}$-series is the largest among them, because here type $\mathrm{A}$ or $\mathrm{B}$ inclusions exist perpendicular to the long axis of the specimens.

Thus, when generalized,

$$
W=i(A-n)
$$

Here, it is assumed that three factors, i.e., size, shape, and amount, of the inclusions influence the endurance limits independently. Therefore:

$$
i=\alpha f(k)+\beta g(l)+\gamma h(m) .
$$

where $k, l$, and $m$ are variables which represent the size, the shape, and the amount of inclusions respectively, and $\alpha, \beta$, and $\gamma$ are constants.

Thus,

$$
W=[\alpha f(k)+\beta g(l)+\gamma h(m)](A-n) .
$$

If $f(k), g(l)$, and $h(m)$ could be expressed by linear functions, it is simple to determine $\alpha, \beta$, and $\gamma$. For instance, the relation between $m$ and $n$ is obtained by keeping $k$ and $l$ constants.

2. A Phenomenological Explanation on Reduction of Endurance Limits owing to Inclusions

Orowan ${ }^{19)}$ had analysed the fatigue fracture as fol-

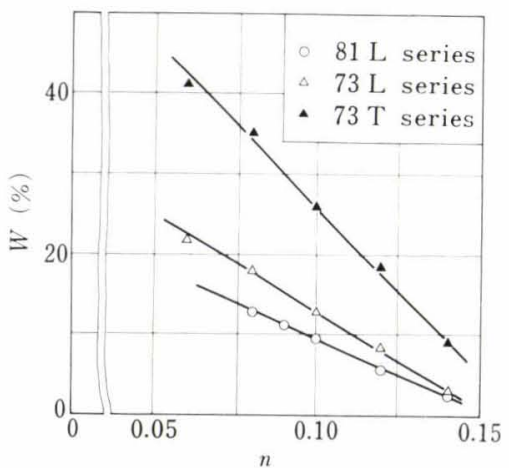

Fig. 8. Relationship between the rate of reduction of endurance limit $(W)$ due to inclusions and workhardening coefficient $(n)$

lows: When a specimen contains local regions with different plastic deformability such as inclusions, the strain amplitude decreases gradually owing to the work hardening under alternating stress of a constant amplitude, while the local internal stress and the total plastic strain increase with cycles; a crack is initiated when the stress reaches the fracture stress $\sigma_{f}$. On the basis of this theory, the crack initiation around inclusions is considered as follows.

The amount of the work hardening for a $1 / 2$ cycle, $\Delta y$, at a strain, $\varepsilon$, at a given place is:

$$
\Delta y=\frac{d \sigma}{d \varepsilon} \varepsilon
$$

On the other hand, the amount of the work hardening for a $1 / 2$ cycle in the region of stress concentration owing to an inclusion, $\Delta y^{\prime}$, is:

$$
\Delta y^{\prime}=K_{s} \Delta y=K_{s} \frac{d \sigma}{d \varepsilon} \varepsilon
$$

where $K_{s}$ is the stress concentration factor. The work hardening coefficient $n$ defined by $\sigma=c \varepsilon^{n}$ is

$$
n=\frac{\varepsilon}{\sigma} \frac{d \sigma}{d \varepsilon}
$$

Therefore, from Eqs. (8) and (9):

$$
\Delta y^{\prime}=K_{s} n^{\prime} \sigma \text {....... }
$$

where $n^{\prime}$ is the dynamical work hardening coefficient. The amount of increase of the internal stress for the half of the first cycle is:

$$
\Delta y_{1}^{\prime}=K_{s} n^{\prime} \sigma_{\omega}
$$

where $\sigma_{\omega}$ is the stress amplitude, which corresponds to the endurance limit that is the lowest stress level required for crack initiation. The amount of increase for the subsequent half cycle, $\Delta y_{2}^{\prime}$, is:

$$
\Delta y_{2}^{\prime}=K_{s} n^{\prime}\left(\sigma_{\omega}+\Delta y_{1}^{\prime}\right)=\sigma_{\omega}\left(K_{s} n^{\prime}+K_{s}^{2} n^{\prime 2}\right) \ldots(10)^{\prime \prime}
$$

In the same way, the amount of increase of the internal stress for the $\left[\mathcal{N}_{i}-\mathcal{N}_{(i-1 / 2)}\right]$ cycle is expressed as follows.

$$
\Delta y_{2 N_{i}}^{\prime}=\sigma_{\omega}\left(K_{s} n^{\prime}+K_{s}^{2} n^{\prime 2}+\ldots+K_{s}^{2 N_{i}} n^{\prime 2 N_{i}}\right) \ldots
$$

In order to reconcile the Orowan's theory to practical S-N curves, the $n^{\prime}$ should be $\left(1 / 10^{2}-1 / 10^{4}\right) n{ }^{10)}$ As the plastic deformation arises prior to the crack initiation from inclusions, ${ }^{15)} K_{s}$ is not the elastic stress concentration factor but a kind of the plastic stress concentration factor, $K_{\sigma(p)}{ }^{13)}$ The maximum 
possible value of $K_{\sigma(p)}$ is independent of root radius, but depends only on the flank angle of the notch, and the $K_{\sigma(p)}^{\max }$ takes a value of less than 3. ${ }^{13)} \quad$ Therefore, the $K_{s}^{\max }$ takes also a value of less than 3 because $K_{s}^{\max }$ is considered to be smaller than $K_{\sigma(p)}^{\max }$. Thus, $K_{s} n^{\prime} \ll 1$. Then,

$$
\Delta y_{2 N_{i}}^{\prime}=\sigma_{\omega} K_{s} n^{\prime}
$$

At a low stress level, $K_{\sigma(p)}$ takes the maximum value at the elastic-plastic interface. Using the Tresca criterion, ${ }^{13)}$

$$
K_{\sigma(p)}=\sigma_{\sigma_{y}}^{\max }=1+\ln \left(1+\frac{R}{\rho}\right)
$$

where $\sigma_{y}^{\max }$ is the maximum tensile stress which exists beneath the root, $\sigma_{y}$ the tensile yield stress of a nonotched specimen tested at the same strain rate, $R$ the plastic zone size, and $\rho$ the root radius. By analogy to Eq. (12), the maximum tensile yield stress which exists at the tip of inclusions is $K_{s} \sigma_{y}$. The $\sigma_{f}$, the crack initiation stress near the tip of inclusions after the work hardening has been saturated under alternating stress, is given by:

$$
\sigma_{f}=K_{s} \sigma_{y}+B \cdot 2 \mathcal{N}_{c} \cdot \Delta y
$$

where $\mathcal{N}_{c}$ is the cycles at the "knees" of $\mathrm{S}-\mathrm{N}$ curves, and $\mathrm{B}$ is a constant. In the present experiment, $\mathcal{N}_{c}$ $=10^{6}$, and $B=1 / 20$, because the cycles needed for the crack initiation is generally about $1 / 20$ of $\mathcal{N}_{c}$.

A certain size of the plastically deformed zone is required for the crack initiation. ${ }^{20)}$ The size of the plastic zone around inclusions, $R^{\prime}$, increases as the size of inclusions increases. As $R^{\prime}$ corresponds to $R$, and $K_{\sigma(p)}$ is a function of $R$ as shown in Eq. (12), $K_{s}$ increases with the size of inclusions. The $K_{\sigma(p)}$ is also a function of $\rho$. Therefore, when the inclusion is spherical, $R^{\prime}$ increases with the size of the inclusion, but $K_{s}$ is independent of the size. Moreover, the stress must reach $\sigma_{f}$ to initiate a crack according to the conception of the work hardening described above. In other words, when a crack is initiated around an inclusion, $R^{\prime}$ and $\sigma$ must have attained the critical values $R^{*}$ and $\sigma_{f}$ respectively. The $R^{*}$ depends on the properties of matrix because the absorbability of strain energy depends on the grain size, the distribution of carbides, etc.

The following empirical equation between the true fracture strength, $\sigma_{f}^{\prime}$, the yield strength, $\sigma_{y}^{\prime}$, and the work hardening coefficient, $n$, is adequate as shown in Fig. 9.

$$
\frac{\sigma_{f}^{\prime}}{\sigma_{y}^{\prime}}=D n+1
$$

where $D$ is a constant $(D=10)$, and $\sigma_{f}^{\prime}=\sigma_{y}^{\prime}$ when $n=0$. Assuming that $\sigma_{f}$ and $\sigma_{y}$ in Eq. (13) are equivalent to $\sigma_{f}^{\prime}$ and $\sigma_{y}^{\prime}$ respectively, from Eqs. $(11)^{\prime}$, (13), and (14):

$$
\sigma_{\omega}=\frac{1}{2 m \mathcal{N}_{c}}\left[\frac{D n+\left(1-K_{s}\right)}{K_{s} n^{\prime}}\right] \sigma_{y}^{\prime}
$$

Equation (15) shows when a crack is initiated at a

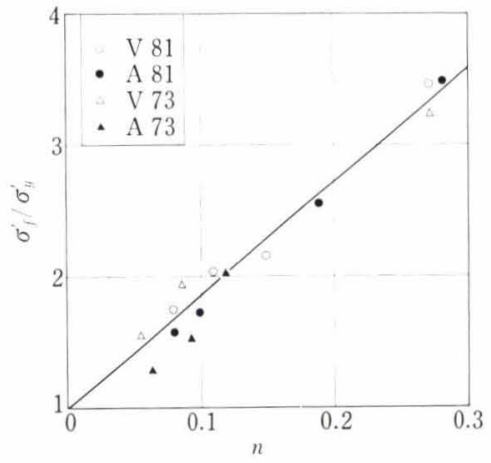

Fig. 9. Relationship between rate of true fracture strength $\left(\sigma_{f}^{\prime}\right)$ to yield strength $\left(\sigma_{y}^{\prime}\right)$ and work-hardening coefficient $(n)$

given inclusion, how the relation between the endurance limit, $\sigma_{w}, n$, and $n^{\prime}$ change with the stress concentration factor of the inclusion. When no inclusion exists, $K_{s}=1$. Then:

$$
\sigma_{\omega}=\frac{1}{2 m \mathcal{N}_{c}}\left(\frac{D n}{n^{\prime}}\right) \sigma_{y}^{\prime}
$$

where, $n=10^{4} n^{\prime}$ so that Eq. (15)' corresponds to the present results because $\mathcal{N}_{c}=10^{6}, B=1 / 20$, and $D=10$ (Fig. 9). Such a value of $n^{\prime}$, small compared to $n$, seems to be a result that $n^{\prime}$ is affected by the recovery of the work hardening.

The recovery mentioned above is equivalent to the dynamical recovery which is observed at the third stage of the deformation process of face centred single crystals. That is, the different sign dislocations that have piled up at an inclusion by the tensile and compressive stresses react each other during alternating stress, and then some of them annihilate themselves, while some others develop into a void. ${ }^{21,22}$ Consequently, the rate of the increase of the flow stress and the work hardening coefficient decrease.

When inclusions exist $\left(K_{s}>1\right)$,

$$
\sigma_{\omega}=\frac{1}{10}\left(\frac{10}{K_{s}}+\frac{1-K_{s}}{K_{s}} \frac{1}{n}\right) \sigma_{y}^{\prime}
$$

The above equation (see Fig. 10) shows that the rate of decrease of the endurance limits due to inclusions increases with the increase of $1 / n$, and the trend is intensified with the increase of $K_{s}$. The relation between $\sigma_{\omega}$ and $1 / n$ on the present materials is almost the same as Fig. 10 as shown in Fig. 11.

Figure 10 was drawn assuming that the source of crack initiation was only one. On the other hand, Fig. 11 was made on the results of the fatigue test on the specimens having many sources, namely, inclusions at which cracks were initiated. Nevertheless, both figures are essentially the same. This appears to show, therefore, that the decrease of the endurance limit owing to inclusions can be explained by the work hardening theory.

\section{Conclusions}

(1) The inclusions in the low carbon steels do not influence the endurance limit regardless the states of 


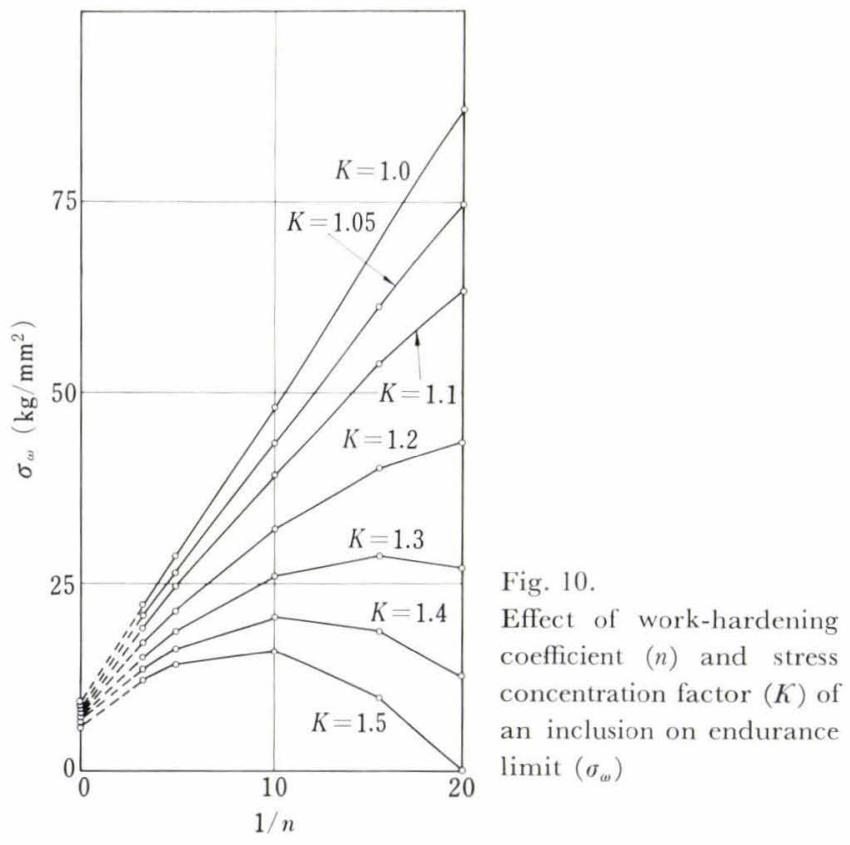

existence of inclusions in the steels.

(2) No effect of the inclusions in the as-carburized specimens is found. Accordingly, it can be said that the high carbon content itself does not promote the adverse influence of inclusions on fatigue properties.

(3) The endurance limits of the carburized and subsequently heat-treated specimens, whose structures are tempered martensite, are decreased by the inclusions. The trend becomes more marked with the decrease of the tempering temperature, namely, with the increase of strength level of the specimens. Moreover, the tendency is considerable when the inclusions of type A or B exist in the specimens that are prepared perpendicular to the rolling direction.

(4) Microcracks are initiated preferentially from the inclusions within $10 \%$ of the fatigue life regardless the magnitude of the effect of the inclusions on the endurance limit.

(5) The effect of the inclusions on the initiation of microcracks increases as the strength level increases.

(6) The endurance limits of the specimens with heterogeneous structure decrease compared to those with homogeneous structure even if at the same tensile strength level, regardless the inclusions. The effect of heterogeneous structure on the endurance limit decreases with the increase of inclusions.

(7) In discussing the effect of inclusions on the fatigue properties of steels, the work hardening coefficient $n$, as defined by $\sigma=c \varepsilon^{n}$, is adequate to represent the property of matrix.

(8) The rate of decrease of the endurance limit owing to inclusions, $W$, is generally shown by;

$$
W=i(A-n)
$$

where $i$ is the variable that represents the state (size, shape, amount, etc.) of inclusions, and $A$ is a constant.

(9) The model, that assumes a crack to be initiated at a certain type of inclusion when the stress

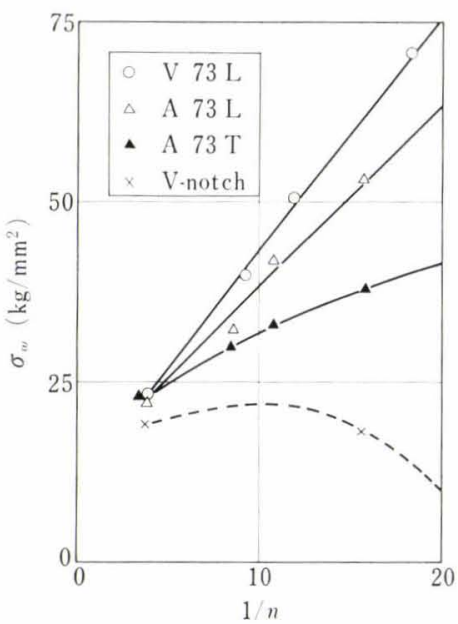

Fig. 11

Relationship between endurance limit $\left(\sigma_{\omega}\right)$ and work-hardening coefficient (n) for varied states of exsistence of inclusions that has been increasing under the given cyclic stress amplitude attains the particular fracture stress (considering the stress concentration at the inclusion) of the particular material, is adequate to explain phenomenologically the observations of (8).

\section{Acknowledgements}

The authors wish to thank Dr. A. Yoshikawa for many helpful discussions.

\section{REFERENCES}

1) R. H. Edwards: J. Appl. Mech., 18 (1951), 19.

2) H. Leiris and M. E. Frappier: Rev. Mét., 54 (1951), 11.

3) R. F. Johnson and J. F. Sewell: JISI, 194 (1960), 414.

4) M. Atkinson: JISI, 195 (1960), 64.

5) E. Orowan: Proc. Roy. Soc., A171 (1939), 79.

6) F. E. Fujita: Sci. Repts. Res. Insts. Tohoku Univ., A6 (1954), 565.

7) F. Seitz: Advan. Phys., 1 (1952), 43.

8) J. Friedel: Phil. Mag., 7 (1955), 1169.

9) N. F. Mott: Proc. Roy. Soc., A242 (1957), 145.

10) T. Yokobori: Strength, Fracture and Fatigue of Materials, (English edition), P. Noordhoff, Groningen, The Netherlands, (1965).

11) J. Friedel: Fracture, Wiley, New York, (1959), 498.

12) P. Paris and F. Erdogan: Trans. ASME, Series D. J. Basic Engng, 85 (1963), 528.

13) A. S. Tetelman and A.J. McEvily, Jr.: Fracture of Structura! Materials. John Wiley \& Sons, Inc., (1966), 307.

14) P. Beardmore and C. E. Feltner: Proc. of the Second International Conference on Fracture, (1969), 607.

15) A. Yoshikawa and M. Okamoto: Trans. JIM, 9 (1968), 471 .

16) N. Thompson, N.J. Wadsworth, and N. Louat: Phil. Mag., 1 (1956), 113.

17) M. Hempel and E. Hilluhagen: Arch. Eisenhüttenw., 39 (1968), 283.

18) L. F. Coffin, Jr. and J. F. Tavernelli: Trans. Met. Soc. AIME, 215 (1959), 794.

19) E. Orowan: Proc. Roy. Soc., A171 (1939), 79.

20) W. S. Iwanova: Fatigue Fracture of Metals, National Science and Technology Publishing Society, Moscow, (1963). (in Japanese), 4.

21) E. Fujita: Sci. Repts. Res. Insts. Tohoku Univ., A6 (1954), 565.

22) A. Kochendorfer: Arch. Eisenhüttenw., 25 (1954), 351. 